\title{
The influence of product and personal attributes on organic food marketing
}

\author{
Catherine Prentice ${ }^{\mathrm{a}}$, Jue Chen ${ }^{\mathrm{b}}$, Xuequn Wang ${ }^{\mathrm{c}, *}$ \\ a Griffith Business School, Griffith University, Brisbane, Australia \\ ${ }^{\mathrm{b}}$ Eco Consulting Pty Ltd, Australia \\ c School of Engineering and Information Technology, Murdoch University, WA 6150, Australia
}

\section{A R T I C L E I N F O}

\section{Keywords:}

Organic food

Food attributes

Food marketing

Consumer behaviour

\begin{abstract}
A B S T R A C T
The study adapts the theory of planned behaviour and proposes organic food-related attributes that constitute perceived behavioural control and individual attributes influence quality assessment and purchase intention. The study analyses these relationships separately for individuals who have purchased organic food and those who have not. Data were collected in two stages and conducted in both online and face-to-face formats. The findings show that surface food attributes in general have no significant influences on either quality assessment or purchase intention for both groups of consumers; whereas the attributes that are reflective of food safety and environment issues do. The latter explain additional variance in both quality assessment and purchase intention. Consumers' purchase styles have significant moderation effects on product quality assessment and purchase intention in both groups. Implications are provided for researchers and practitioners to conclude the paper.
\end{abstract}

\section{Introduction}

Numerous studies on organic food (e.g. Aertsens et al., 2011; Arvola et al., 2008; Chen, 2007; Tarkiainen and Sundqvist, 2005) have used the theory of planned behaviours (TPB) proposed by Ajzen (1991) to explain and understand consumers' purchase intention and behaviours. Consistent with the theory, consumers' attitudes, social norms and perceived behavioural control are predictive of their behavioural intentions and subsequent purchase of organic food. Organic food is commonly perceived as being safe, healthy and nutritious (Rimal et al., 2005; Tsakiridou et al., 2008). Nonetheless, research shows that these positive attitudes have not led to a large proportion of regular purchase (Aertsens et al., 2009; Aertsens et al., 2011). The market share of organic food remains low across countries (Aertsens et al., 2011).

The relationship between subjective norm and purchase intention is also inconclusive (see Aertsens et al., 2009). Subjective norm refers to perceived social pressure for an individual to engage or not to engage in a behaviour that is influenced by judgement of significant others (Ajzen, 1991). However, rather than relating to behavioural intentions, studies found that subjective norm is associated with attitude towards organic food (Gotschi et al., 2007; Tarkiainen and Sundqvist, 2005). Bamberg and Moser's (2007) meta-analytical study using structural equation modelling find that subjective norm in the context of proenvironmental behaviour has indirect effect on attitude, perceived behavioural control and moral norms, whilst other studies (Chen, 2007; Dean et al., 2008; Thøgersen, 2007b) did find a significant positive relationship between subjective norm and organic food purchase intention.

Researchers (e.g. Bamberg and Möser, 2007; Kaiser, 2006) suggest subjective normal should be extended to include personal norm to understand the impact of normative beliefs. Personal norm in organic food research is construed as moral norm which elicits pro-environmental behaviours such as organic food purchase and consumption (Aertsens et al., 2011). However, such norm and its impact are often affected by personal attributes (e.g. egoistic values) (Stern, 2000). Organic food purchase is knowingly a pro-environmental behaviour. If proposition for normative beliefs is confirmed, the relationship between the norms (either subjective or personal) and purchase intention or actual purchase should be consistent. On the basis of inconsistent findings from prior research, the current study argues that organic food purchase and consumption is a personal choice, rather than under influence of social norms per se. The personal choice is elicited by consumers' personal attributes such as individual purchasing styles (e.g. self-indulgent, variety seeking) (Lobo and Chen, 2012). Purchasing organic food is more an indivdiual choice rather than internalised social norms (Eisinger-Watzl et al., 2015; Thøgersen, 2007b).

The impact of perceived behavioural control on organic food purchase is evidently complex (Aertsens et al., 2009). Whilst Ajzen (1991) proposes that perceived behavioural control may facilitate or impede one's behaviour, in the case of organic food, researchers (Dean et al., 2008; Thøgersen, 2007a) found it significantly relates to intention to purchase some organic products, not significant to others. These

\footnotetext{
* Corresponding author.

E-mail addresses: cathyjournalarticles@gmail.com (C. Prentice), juechen24@gmail.com (J. Chen), xuequnwang1600@gmail.com (X. Wang).
} 
findings indicate that purchase intention is dependent upon various factors including perceived barriers and abilities that influence subsequent behaviours. The barriers and abilities are primarily reflected in organic food price, affordability, and product attributes that are associated with trust in the certification process of organic food (see Aertsens et al., 2011; Lea and Worsley, 2005; Padel and Foster, 2005). Price and affordability are explicit factors affecting consumers' intention to purchase organic food and actual purchase (Hughner et al., 2007; Padel and Foster, 2005). Very few studies have attempted to understand the influence of trust-related food attributes on organic food consumption and purchase.

Price has been factored into organic food purchase as it is associated with consumers' affordability (e.g. Lee and Yun, 2015; Padel and Foster, 2005; Tarkiainen and Sundqvist, 2005). However, Lobo and Chen (2012) found that consumers in China prefer more expensive imported organic food. Their study reveals that Chinese regard imported products better quality and more trusted and opt for them as their first choice despite higher prices. The finding contrasts to that of other studies conducted in most developed countries (Millock et al., 2004; Moore, 2006; Siamagka and Balabanis, 2015). For instance, organic food buyers in the USA rate locally grown products as an important factor influencing their purchase decision (Howard and Allen, 2006). UK consumers are not keen to purchase organic meat from other countries (McEachern and Willock, 2004). Norwegian consumers regard locally produced organic food as being safer and better quality than imported products which are generally cheaper (Torjusen et al., 2001). Consumers in Denmark and Ireland rather buy domestically produced conventional food than foreign produced organic food (Millock et al., 2004; Moore, 2006). These studies indicate that price is a less important factor of organic food purchase and consumption. In the case of China where food safety scandals are ubiquitous (Euromonitor International, 2015), the attributes that are reflective of consumers' trust on food quality ought to be important for consumers to feel worthiness of purchasing expensive organic food.

Consistent with the foregoing discussion, the current study adapts the TPB model and examines the influence of food quality attributes and consumers' personal attributes on food quality and those that on consumers' attitude and purchase intention with a focus on Chinese market. The quality attributes form factors in consumers' behavioural control. On this basis, the attributes selected for this study include surface food traits and non-food traits. The former attributes are indicative of product appearance, fresheness, texture, smell, taste and so on. These traits, according to Torjusen et al. (2001), can be referred to as observation traits. Non-food traits are indicative of ethical, enviornmental and health attributes, including food labels, government control, certification and so on. These traits are referred to as reflection traits (Torjusen et al., 2001). The current study contributes to the literature by clarifying the effect of reflection traits on consumers' quality assessment and organic food purchase.

To gain better insights, this study engages two groups of consumers into the investigation: one group who have purchased organic food, hereafter referred to as experienced consumers (hereafter EC); the other who have not, referred to as prospective consumers (PC). Results from this option would provide practitioners with more insightful information to adjust and optimize their marketing practice. The study also sheds lights on application of TPB on inactive markets in organic food research.

\section{Literature review}

\subsection{Organic food quality attributes}

Review of the relevant literature indicates that food quality and safety (the latter in particular) are the two primary reasons driving organic food purchase and consumption (Ho et al., 2006; Michaelidou and Hassan, 2008; Röhr et al., 2005). Quality is often associated with observation traits including food texture, appearance, smell, nutritional value (Magnusson et al., 2003; Torjusen et al., 2001). Nevertheless, researchers (Zhao et al., 2007) argue that these observation traits are not sufficient to differentiate organic food from conventional one. Consumers are more concerned of reflection traits that are indicative of safety and healthiness (see Bavec and Bavec, 2006). This is particularly important in the case of Chinese consumers given the prevalence of food safety scandals. These traits are reflective of ethical, environmental and health issues (i.e. government regulation on food labelling, logos, certification, labelling, packaging, branding etc.). Safety and healthiness are mostly reflective in food production processes (Torjusen et al., 2001). Since consumers are not directly involved in this process, the reflection traits may help them assess food quality and safety (O’Donovan and McCarthy, 2002).

Consumers are generally unable to differentiate quality of organic food from that of conventional food without the reflection traits (Krystallis et al., 2006). They often rely on labels to determine food quality and attributes (Fotopoulos and Chryssochoidis, 2002). The labels contain contents of food quality and health informaiton such as articifcal flavours or colouring. Tsakiridou et al. (2006) found that food labels had a significant influence on consumers' assessment of organic food and ultimate purchases. However, some authors (e.g. Krystallis and Chryssohoidis, 2005) indicate that consumers have a relatively poor understanding of the legal use of the term 'organic food products'. Other indicators such as organic food logo, packaging, branding, certification help consumers assess product quality (Botonaki et al., 2006). Their assessments of food quality influence their subsequent purchase (Chryssochoidis, 2000; Torjusen et al., 2001). Research to date has not examined these factors in an integrative manner. Consistent with foregoing discussion, the current study offers the following hypotheses:

H1a. Reflection traits associated with organic food have a significant influence on quality assessment.

H1b. Reflection traits associated with organic food have a significant influence on purchase intention.

H2a. Reflection traits explain additional variance in quality assessment above and beyond the variance explained by observation traits.

H2b. Reflection traits explain additional variance in consumers' purchase intention above and beyond the variance explained by observation traits.

H3. Consumers' quality assessment of organic food has a significant influence on their purchase intention.

\subsection{Personal attributes}

Research shows that organic food purchase is largely influenced by consumers' attitudes towards product quality and food safety (Chryssochoidis, 2000; Torjusen et al., 2001). Only 4-10\% of consumers who hold positive assessment would actually purchase organic food (Magnusson at al, 2003). Shepherd et al. (2005) found that positive attitudes towards organic food do not always lead to purchase. Some researchers apply TPB model to explain consumers' intention to purchase organic products by including the influence of social norms (subjective, personal and moral norms) (e.g. Aertsens et al., 2011; Arvola et al., 2008; Chen and Lobo, 2012). Organic food purchase and consumption are regarded as pro-environmental behaviours. Hence, social norms should explain a big portion of purchase intention. However, findings on this relationship from prior studies are inconclusive. Some studies (Gotschi et al., 2007; Tarkiainen and Sundqvist, 2005) found that social norms are not related to purchase intention.

Researchers (e.g. Chen, 2009; Lockie et al., 2002; Williams and Hammitt, 2000) suggest that organic food consumption is a personal choice, rather than following subjective and/or personal norms which result in moral behavioural consequences. Organic food is knowingly 
more expensive than conventional one. Purchasing organic food ought to relate to affordability and the portion of disposable income. Over last three decades, China underwent dramatic economic transformation and financial prosperity. These changes have largely influenced residents' disposable income which allows them to pursue affluent lifestyles. However, despite ubiquitous food safety issues in China, organic food purchase is rather limited (Euromonitor International, 2015). Lobo and Chen's study (2012) reveal that organic food consumption in China is related to individual purchase style. Purchasing expensive organic products has become a means to indulge oneself and seek food variety (Chen and Lobo, 2012).

Whilst individual purchasing style may be related to ultimate purchase, the current study argues it moderates consumers' purchase intention rather than determine the intention. Purchasing style such as self-indulgence is reflective of impulsive purchase. Such impulse is only activated at the point of sale, which is dependent upon prior knowledge of organic food (e.g. food attributes). Observation traits (e.g. appearance, smell) may stimulate consumers' purchase impulse; reflection traits may prompt consumers' variety seeking tendency since these traits (e.g. brand, logos) are indicative of food varieties. This discussion informs the following hypotheses:

H4a. Individual lifestyle moderates the relationship between the observation traits associated with organic food and purchase intention.

H4b. Individual lifestyle moderates the relationship between reflection traits associated with organic food and purchase intention.

\section{Method}

\subsection{Participants and data collection procedure}

Organic food is relatively new to Chinese consumers, mostly available in large supermarkets in major Chinese cities (Li et al., 2005). Hence, the study was undertaken at major supermarkets in four selected cities in China: Beijing, Shanghai, Shenzhen and Chengdu. All participating supermarkets had organic food sections. Researchers (Drichoutis et al., 2007) indicate that such study conducted in food outlets of retail chains is an efficient method. The selected cities are geographically dispersed, i.e. located in the north, south, east and west of China respectively. Organic food, compared to conventional food, are quite pricy. These four cities, commonly regarded as the major economic engines of China, are large in scale and economically affluent. Citizens in these cities are more affordable for a high level of consuming goods and more aware of organic food.

\subsection{Measures}

Consistent with Torjusen et al.' (2001) classifications of observation and reflection traits, all traditional food quality aspects and reflective attributes were included in the study. After factor analysing them in the pilot study, the items that were significantly loaded on the corresponding factors were remained for further analyses. As a result, taste, smell, and appearance were included as observation traits, price, labelling, government regulations, brand, health effect, certification as reflection traits.

Two purchasing styles were selected for the purpose of this study: self- indulgence and variety seeking. Items used to measure self-indulgence include, for example, "When I like something, I will buy it without too much deliberation", and "I always do whatever I feel like and whenever I feel like it". Variety seeking was to measure people's assessment toward fashionable products, including items "I always try something new and unique", and "I love fashionable and trendy products".

Organic food purchase intention in this study includes PC's purchase intention and EC's repurchase intention. Purchase intention was measured by adapting three items from Bower (2001), including items "I intend to try out organic food products", "I am interested in experiencing the benefits of using organic food", and "It is likely that I will buy organic food products when they become available." Repurchase intention was measured by adapting three items from Cronin Jr. et al. (2000) to assess consumers' future purchase intention, including items "I will probably purchase organic food products again in the future", "I will recommend usage of organic food to my friends and relatives", and "If I had to purchase organic food again, I would make the same choice".

\subsection{Procedures}

The original survey in English was translated to Chinese by a professional translator, and back-translated to English to ensure consistency and accuracy. Items were modified to suit the Chinese context after consulting 24 consumers in China who regularly purchase organic food. Data were collected in two phases. The first was conducted online through Opinio platform. The survey link was sent to selected Chinese food outlets for onward submission to their customers. The sampling frame was drawn using the customer mailing list of the food outlets. Four-hundred and five participants logged onto the web link, but only 200 valid online responses were generated over one month. After analysing the online data, the questionnaires were modified for subsequent paper-based survey.

Shoppers from selected shopping malls in the four cities were approached by trained research assistants and asked to participate in the survey at the main entrance of supermarkets. The assistants were instructed to seek out demographic variation. The surveys were presented to customers leaving these supermarkets throughout the day during the stores' trading hours, including mornings, afternoons and evenings in order to capture customers of different kinds. Most likely house wives and retirees shop during the day (office hours). Evening period is for those who have just finished work. This sampling approach is deemed to be more representative of the population (Gundersen and Jensen, 1987). Shoppers who walked out of the supermarket and had just finished shopping were invited to participate in the survey at a designated area near the shop entrance where participants could sit down to complete the survey. They were advised that the participation was voluntary, and that they could terminate the survey at their own discretion. Should they decide to proceed, the completed survey was requested to hand back to the field research assistants who were present at the survey.

A small gift (e.g. organic nuts, vegetables, milk) was offered in appreciation of their time to answer the questions. The paper-based data were collected over a period of four weeks. Previous studies (Fotopoulos and Krystallis, 2002; Kuhar and Juvancic, 2010; Magnusson et al., 2003; McEachern and Willock, 2004; Roddy et al., 1996) suggest that a sample size of more than 1000 respondents is sufficient to conduct a national survey. Out of 2000 surveys (500 in each city) that were distributed, 778 valid responses were obtained. The response rate is acceptable as extant literature suggests that achieving a $40-50 \%$ response rate in the case of specialised goods like organic food is considered good (Honkanen et al., 2006; Tregear et al., 1994). Table 1 shows the demographic information of the respondents.

\section{Analysis and result}

\subsection{Data analysis}

Multi-item measures of the study variables were factor analysed to confirm reliability and validity. Confirmatory Factor Analysis and maximum likelihood estimation were used to determine the model fit (Hu and Bentler, 1999). The results show that the model produced $\chi^{2}$ $(233)=816.28, p<.000$, SRMR $=.04$ and RMSEA $=.05$, CFI $=.96$ and TLI $=.95$, indicating a good model fit. As shown in Table 2, all 
Table 1

Demographic information of this study.

\begin{tabular}{lll}
\hline Variables & $\mathrm{N}$ & Percentage \\
\hline Female & 320 & $41.1 \%$ \\
Male & 458 & $58.9 \%$ \\
Between 18-30 & 82 & $10.6 \%$ \\
Between 31-45 & 142 & $18.2 \%$ \\
Between 46-60 & 192 & $24.7 \%$ \\
Greater than 60 & 362 & $46.6 \%$ \\
Below high school & 74 & $9.5 \%$ \\
High school & 127 & $16.3 \%$ \\
2 years college or associate's degree & 172 & $22.1 \%$ \\
Bachelor degree & 324 & $41.6 \%$ \\
Postgraduate or above & 81 & $10.4 \%$ \\
Less than RMB 5, 000 & 327 & $42.0 \%$ \\
Between RMB 5, 001-10,000 & 267 & $34.3 \%$ \\
Between RMB 10, 001-20,000 & 133 & $17.1 \%$ \\
More than RMB 20, 000 & 51 & $6.6 \%$ \\
Beijing & 167 & $21.5 \%$ \\
Shanghai & 237 & $30.5 \%$ \\
Shenzhen & 168 & $21.6 \%$ \\
Chengdu & 206 & $26.5 \%$ \\
\hline
\end{tabular}

items have significant loadings on their corresponding constructs. The composite reliabilities for all factors were acceptable, and the average variance extracted (AVE) for each factor was over .50, indicative of adequate convergence (Fornell and Larcker, 1981). The results of standardized residuals and modification indices show no conspicuously significant changes to the model. Table 3 shows the correlations among the factors. The square root of average variance extracted for each construct exceeds the correlation between constructs, indicating discriminant validity.

\subsection{Hypothesis testing}

The respondents are divided into two groups as discussed before (i.e. PC and EC). Consistent with Wulf et al.'s (2001) approach, a multigroup analysis was conducted to assess whether the examined relationships differ between PC and EC. The results show that the chisquare of the model with all parameters constrained for the two groups significantly differs from that of the unconstrained model $(\Delta \chi 2(132)=$ 178.31, $p<.01$ ), indicating PC and EC are different in their
Table 3

Correlations and square root of AVE (diagonal).

\begin{tabular}{|c|c|c|c|c|c|c|c|c|c|c|}
\hline & PI & RPI & QA & SI & VS & $\mathrm{L}$ & GR & B & $\mathrm{HE}$ & $\mathrm{C}$ \\
\hline PI & .81 & & & & & & & & & \\
\hline RPI & $.55^{* * *}$ & .78 & & & & & & & & \\
\hline QA & $.35^{* *}$ & $.39^{* * *}$ & .71 & & & & & & & \\
\hline SI & $.08^{*}$ & $.17^{\text {k** }}$ & $.12^{* * *}$ & .91 & & & & & & \\
\hline VS & $.24^{\text {क* }}$ & $.19^{\text {kisk }}$ & $.10^{* \text { *kt }}$ & $.34^{* \text { tik }}$ & .91 & & & & & \\
\hline $\mathrm{L}$ & $.24^{* *}$ & $.26^{* * *}$ & $.38^{\text {*t* }}$ & $.25^{* *}$ & $.15^{\text {k** }}$ & .71 & & & & \\
\hline GR & $.18^{* * *}$ & $.21^{\text {**x }}$ & $.28^{* * *}$ & $.13^{* * *}$ & $.17^{\text {kek }}$ & $.22^{\text {k*k }}$ & .77 & & & \\
\hline B & $.23^{* * *}$ & $.31^{* * *}$ & $.37^{* * *}$ & $.15^{* * *}$ & .05 & $.28^{k * * *}$ & $.22^{* * *}$ & .71 & & \\
\hline HE & $.25^{* *}$ & $.27^{* * *}$ & $.40^{* * 1 *}$ & $.11^{* * *}$ & .06 & $.31^{k \text { kn }}$ & $.22^{* * *}$ & $.37^{* / *}$ & .78 & \\
\hline C & $.32^{\text {** }}$ & $.23^{\text {**x }}$ & $.21^{* * *}$ & -.03 & .07 & $.12^{* * *}$ & $.17^{* \text { *k }}$ & .03 & .00 & .79 \\
\hline
\end{tabular}

Note: PI = Purchase intention, RPI = Repurchase intention, $\mathrm{QA}=$ Quality assessment, $\mathrm{SI}$ $=$ Self-indulgence, $\mathrm{VS}=$ Variety seeking, $\mathrm{L}=$ Labelling, $\mathrm{GR}=$ Government regulations, $\mathrm{B}=$ brand, $\mathrm{HE}=$ Heath effect, $\mathrm{C}=$ Certification.

* Correlation is significant at the .05 level (2-tailed).

$* *$ Correlation is significant at the .01 level (2-tailed).

Table 4

Ranking of organic food traits.

\begin{tabular}{lll}
\hline & Prospective consumers & Experienced consumers \\
\hline Observation traits & & \\
Taste & 3.83 & 3.80 \\
Smell & 3.81 & 3.73 \\
Appearance & 3.18 & 3.39 \\
Reflection traits & & \\
Certification & 4.39 & 4.24 \\
Labelling & 4.09 & 4.08 \\
Government regulations & 4.04 & 3.85 \\
Price & 4.00 & 3.91 \\
Brand & 3.59 & 3.47 \\
Heath effect & 3.46 & 3.64 \\
\hline
\end{tabular}

assessments and purchase intentions.

As the current study proposes that reflection traits explain additional variance in Chinese consumers' organic food quality assessment and their purchase intention, we ranked relevant importance of both observation and reflection traits on the basis of respondents' assessment prior to testing the hypotheses. The rankings were calculated by averaging the scores of items for each trait. As shown in Table 4 and Fig. 1,

Table 2

Confirmatory factor analyses results.

\begin{tabular}{|c|c|c|c|c|c|}
\hline & Item & FL & $\alpha$ & $\mathrm{CR}$ & AVE \\
\hline \multirow[t]{3}{*}{ Purchase intention } & I intend to try out organic food products & .66 & .75 & .86 & .66 \\
\hline & I am interested in experiencing the benefits of using organic food & .69 & & & \\
\hline & It is likely that I will buy organic food products when they become available & .76 & & & \\
\hline \multirow[t]{3}{*}{ Repurchase intention } & I will probably use organic food products in the future & .67 & .68 & .82 & .61 \\
\hline & I will recommend usage of organic food to my friends and relatives & .62 & & & \\
\hline & If I had to purchase organic food again, I would make the same choice & .64 & & & \\
\hline \multirow[t]{2}{*}{ Self-indulgence } & When I like something, I will buy it without too much deliberation & .75 & .79 & .90 & .82 \\
\hline & I always do whatever I feel like and whenever I feel like it & .88 & & & \\
\hline \multirow[t]{2}{*}{ Variety Seeking } & I always try something new and unique & .83 & .80 & .91 & .83 \\
\hline & I love fashionable and trendy products & .80 & & & \\
\hline \multirow[t]{2}{*}{ Quality Assessment } & I believe organic food has superior quality. & .74 & .65 & .68 & .51 \\
\hline & Organic foods are high quality products. & .65 & & & \\
\hline \multirow[t]{2}{*}{ Labelling } & When I buy a food product, I always read the label. & .70 & .68 & .67 & .50 \\
\hline & I can recall the labelling of some of the organic food products. & .72 & & & \\
\hline \multirow[t]{2}{*}{ Government Regulations } & Chinese government regulate food marketing, and have developed significant policies. & .81 & .74 & .75 & .60 \\
\hline & Lack of adequate government control of media allows advertisers to take advantage of consumers. & .73 & & & \\
\hline \multirow[t]{2}{*}{ Brand } & I like the brands associated with organic food. & .64 & .67 & .67 & .51 \\
\hline & I can recall the brand names of some of the organic food products. & .78 & & & \\
\hline \multirow[t]{2}{*}{ Health effect } & Organic food is good for myself and my family's health. & .82 & .76 & .76 & .61 \\
\hline & Organic food has no harmful effects. & .74 & & & \\
\hline \multirow[t]{2}{*}{ Certification } & I trust organic food certification bodies & .76 & .76 & .76 & .62 \\
\hline & I trust the outlets which sell certified organic food & .81 & & & \\
\hline
\end{tabular}

Note: $\alpha=$ Cronbach's alpha, $\mathrm{FL}=$ factor loadings, $\mathrm{CR}=$ composite reliability, $\mathrm{AVE}=$ average variance extracted. 


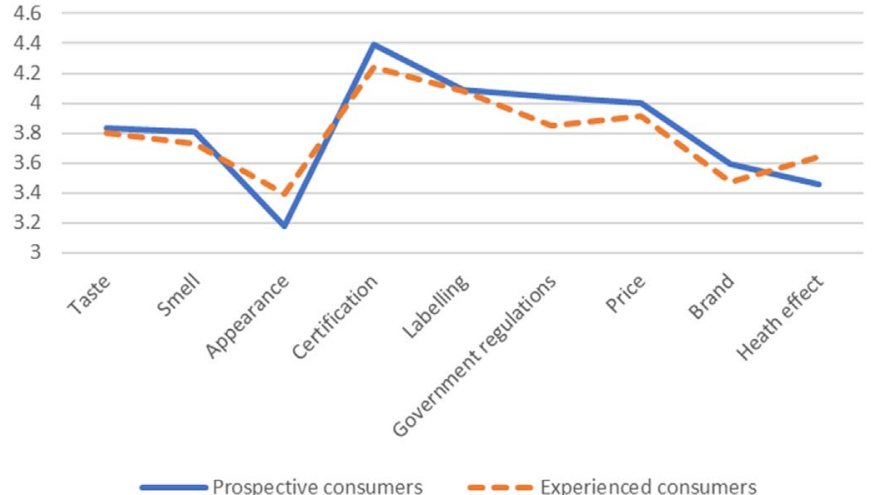

Fig. 1. Organic food traits assessment between prospective and experienced consumers.

EC and PC perceive different traits quite similarly. For observation traits, taste is perceived as the most important trait, while the appearance is perceived as the least important trait; for reflection traits, certification is perceived as the most important trait for PC and EC, whereas EC perceive brand as the least important.

Hypotheses H1-3 propose the relationships between organic food traits and individual assessment of organic food quality, between quality assessment and purchase intention/ repurchase intention. For PC, we use purchase intention as the dependent variable, and the results (shown in Fig. 2 and Table 5) show that none of observation traits have significant influences on PC's assessment of organic food quality; while the reflection traits, labelling $(\beta=.19, p<.05)$, health effect $(\beta=.21$, $p<.01)$ and certification $(\beta=.17, p<.05)$ have significant effects. After controlling observation traits, all effects remain significant in explaining quality assessment. Organic food quality assessment also substantially affects purchase intention $(\beta=.38, p<.001)$. The analyses also show that price, labelling, and certification have direct effects on PC's purchase intention. The mediation effect of food quality assessment was also assessed. As shown in Table 5, in the case of prospective organic food consumers, after quality assessment was controlled, the effects between organic food traits and purchase intention were reduced. Specifically, the effect of price, labelling, and certification on purchase intention decreased, showing that quality assessment partially mediated the relationship between organic food traits and purchase intention.

In the case of EC, repurchase intention was included as the outcome variable. The results are present in Fig. 2 and Table 5. Again, none of observation traits have significant influences on EC's assessment of organic food quality. For reflection traits, labelling $(\beta=.20, p<.001)$, government regulation $(\beta=.11, p<.01)$, brand $(\beta=.18, p<.001)$, heath effect $(\beta=.24, p<.001)$ and certification $(\beta=.16, p<.001)$ have significant effects on assessment of organic food quality. All effects remain significant after controlling the effects of observation traits. Organic food quality assessment has a significant effect on purchase intention $(\beta=.38, p<.001)$. The analyses also show that brand, health effect, and certification have direct effects on EC's purchase intention. The mediation effect of food quality assessment was also assessed. As shown in Table 5, the mediation modelling test shows that the effects of brand, health effect and certification were reduced after

\section{Organic Food Traits}

\section{Observation traits}

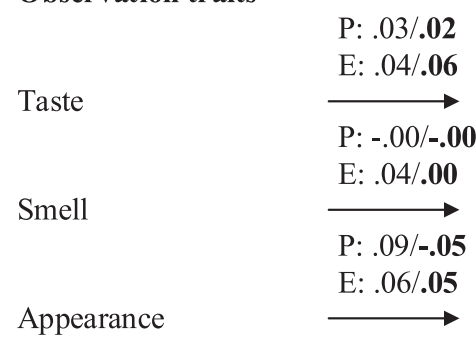

Reflection traits

\begin{tabular}{|c|c|}
\hline & $\begin{array}{l}\text { P: } .09 / .26 * * \\
\text { E: } .03 / .06\end{array}$ \\
\hline Price & $\begin{array}{l}\longrightarrow \\
\text { P: } .18^{*} / .21 * * \\
\text { E: } .19^{* * *} / .07\end{array}$ \\
\hline Labelling & $\begin{array}{l}\longrightarrow \\
\mathrm{P}: .08 /-.06 \\
\mathrm{E}: .10^{* * / .04}\end{array}$ \\
\hline Government regulations & $\begin{array}{l}\longrightarrow \mathrm{P}: .13 / .07 \\
\mathrm{E}: .17 * * * / .15 * * *\end{array}$ \\
\hline Brand & $\begin{array}{l}\longrightarrow \\
\text { P: } .21 * * / .09 \\
\text { E: } .23 * * * / .14 * *\end{array}$ \\
\hline Health effect & $\begin{array}{l}\longrightarrow \\
\mathrm{P}: 15^{*} / .34 * * * \\
\mathrm{E}: 15^{* * *} / .22 * * *\end{array}$ \\
\hline
\end{tabular}

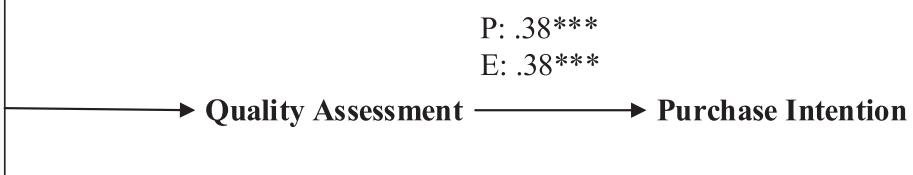

P: Prospective consumers

E: Experienced consumers

$* p<.05$

$* * p<.01$

$* * * p<.001$

The numbers in bold represent the direct effects of organic food traits on purchase intention. 
Table 5

Results of mediation model testing: quality assessment as a mediator between organic food attributes and purchase intention (prospective consumers) / repurchase intention (experienced consumers)

\begin{tabular}{|c|c|c|c|c|c|c|}
\hline \multirow[b]{2}{*}{ Structural path } & \multicolumn{3}{|c|}{ Prospective consumers } & \multicolumn{3}{|c|}{ Experienced consumers } \\
\hline & $\mathrm{DE}$ & Mediation & $\mathrm{FM}$ & $\mathrm{DE}$ & Mediation & FM \\
\hline \multicolumn{7}{|l|}{ Observation traits } \\
\hline Taste $\rightarrow$ Quality & & & .03 & & & .04 \\
\hline Smell $\rightarrow$ Quality & & & -.00 & & & .04 \\
\hline Appear $\rightarrow$ Quality & & & .09 & & & .06 \\
\hline \multicolumn{7}{|l|}{ Reflection traits } \\
\hline Price $\rightarrow$ Quality & & .11 & .09 & & .05 & .03 \\
\hline Label $\rightarrow$ Quality & & $.19^{*}$ & $.18^{*}$ & & $.20^{* * k * k}$ & $.19^{k * * * k}$ \\
\hline Govern $\rightarrow$ Quality & & .09 & .08 & & $.11^{n+k}$ & $.10^{k * i k}$ \\
\hline Brand $\rightarrow$ Quality & & .14 & .13 & & $.18^{3 * k * k}$ & $.17^{* * * * x}$ \\
\hline Heath $\rightarrow$ Quality & & $.21^{* * k}$ & $.21^{k * *}$ & & $.24^{* \ldots * k}$ & $.23^{k * * * *}$ \\
\hline Certify $\rightarrow$ Quality & & $.17^{*}$ & $.15^{*}$ & & $.16^{* \ldots * *}$ & $.15^{* * * * *}$ \\
\hline $\mathrm{R}^{2}$ & & .28 & .29 & & .32 & .33 \\
\hline Quality $\rightarrow$ PI & $.38^{2, k \times k n}$ & & & $.38^{k+k \times k}$ & & \\
\hline $\mathrm{R}^{2}$ & .15 & & & .14 & & \\
\hline Taste $\rightarrow$ PI & .02 & & .02 & .06 & & .05 \\
\hline Smell $\rightarrow$ PI & -.00 & & .00 & .00 & & -.00 \\
\hline Appearance $\rightarrow$ PI & -.05 & & -.07 & .05 & & .04 \\
\hline Price $\rightarrow$ PI & $.26^{* * *}$ & & $.24^{* * *}$ & .06 & & .05 \\
\hline Labelling $\rightarrow$ PI & $.21^{2 k+k}$ & & $.18^{*}$ & .07 & & .03 \\
\hline Government $\rightarrow$ PI & -.06 & & -.08 & .04 & & .02 \\
\hline Brand $\rightarrow$ PI & .07 & & .05 & $.15^{t+k \times *}$ & & $.12^{* * i}$ \\
\hline Heath $\rightarrow$ PI & .09 & & .05 & $.14^{t * k}$ & & $.09^{*}$ \\
\hline Certification $\rightarrow$ PI & $.34^{2 * k * * *}$ & & $.31^{* * * * x}$ & $.22^{* k * k}$ & & $.19^{* * * * *}$ \\
\hline $\mathrm{R}^{2}$ & .30 & & .33 & .19 & & .22 \\
\hline
\end{tabular}

Govern $=$ government regulation, $\mathrm{PI}=$ purchase intention, $\mathrm{DE}=$ direct effect, $\mathrm{FM}=$ full model.

$* p<.05$.

$* * p<.01$

$* * * p<.001$

Table 6

Results of H2a Testing.

\begin{tabular}{|c|c|c|c|c|}
\hline \multirow[t]{2}{*}{ Structural path } & \multicolumn{2}{|c|}{ Prospective consumers } & \multicolumn{2}{|c|}{ Experienced consumers } \\
\hline & OTM & OTRM & OTM & OTRM \\
\hline \multicolumn{5}{|l|}{ Observation traits } \\
\hline Taste $\rightarrow$ Quality & .08 & .03 & $.23^{* * * *}$ & .04 \\
\hline Smell $\rightarrow$ Quality & .13 & -.00 & $.10^{*}$ & .04 \\
\hline Appear $\rightarrow$ Quality & .16 & .09 & $.10^{*}$ & .06 \\
\hline \multicolumn{5}{|l|}{ Reflection traits } \\
\hline Price $\rightarrow$ Quality & & .09 & & .03 \\
\hline Label $\rightarrow$ Quality & & $.18^{*}$ & & $.19^{* 2 * k+k}$ \\
\hline Govern $\rightarrow$ Quality & & .08 & & $.10^{* *}$ \\
\hline Brand $\rightarrow$ Quality & & .13 & & $.17^{\text {*k⿲kek }}$ \\
\hline Heath $\rightarrow$ Quality & & $.21^{* * *}$ & & $.23^{* * \times * x}$ \\
\hline Certify $\rightarrow$ Quality & & $.15^{*}$ & & $.15^{* * * k}$ \\
\hline $\mathrm{R}^{2}$ & .09 & .29 & .11 & .33 \\
\hline$\Delta \mathrm{R}^{2}$ & & $.20^{* k * k}$ & & $.22^{* 2 \times k x}$ \\
\hline
\end{tabular}

Govern = government regulation, OTM = model with observation traits, OTRM = model with both observation and reflection traits.

$$
\begin{aligned}
& * p<.05 . \\
& { }^{* *} p<.01 . \\
& * * * p<.001 .
\end{aligned}
$$

controlling food quality assessment. Therefore, quality assessment partially mediated the relationship between organic food traits and purchase intention. On the basis of these findings, $\mathrm{H} 1 \mathrm{a}$ and $\mathrm{H} 1 \mathrm{~b}$ are partially supported; whereas H3 is confirmed.

$\mathrm{H} 2 \mathrm{a}$ and $\mathrm{H} 2 \mathrm{~b}$ propose that reflection traits explain additional variance in quality assessment and purchase intention beyond the variance explained by observation traits. As shown in Tables 6,7 , reflection traits explained additional variance in quality assessment and purchase

\begin{tabular}{|c|c|c|c|c|}
\hline \multirow[t]{2}{*}{ Structural path } & \multicolumn{2}{|c|}{ Prospective consumers } & \multicolumn{2}{|c|}{ Experienced consumers } \\
\hline & OTM & OTRM & OTM & OTRM \\
\hline \multicolumn{5}{|l|}{ Observation traits } \\
\hline Taste $\rightarrow$ PI & .07 & .02 & $.19^{k * * * *}$ & .06 \\
\hline Smell $\rightarrow$ PI & .15 & -.00 & .05 & .00 \\
\hline Appear $\rightarrow$ PI & .04 & -.05 & $.09^{*}$ & .05 \\
\hline \multicolumn{5}{|l|}{ Reflection traits } \\
\hline Price $\rightarrow$ PI & & $.26^{* *}$ & & .06 \\
\hline Label $\rightarrow$ PI & & $.21^{\mathrm{k*}}$ & & .07 \\
\hline Govern $\rightarrow$ PI & & -.06 & & .04 \\
\hline Brand $\rightarrow$ PI & & .07 & & $.15^{* * * * *}$ \\
\hline Heath $\rightarrow$ PI & & .09 & & $.14^{* * *}$ \\
\hline Certify $\rightarrow$ PI & & $.34^{* * * *}$ & & $.22^{* * * *}$ \\
\hline $\mathrm{R}^{2}$ & .04 & .30 & .07 & .19 \\
\hline$\Delta \mathrm{R}^{2}$ & & $.26^{* * *}$ & & $.13^{* x * \pi}$ \\
\hline
\end{tabular}

Table 7

Results of H2b Testing.

Govern $=$ government regulation, $\mathrm{PI}=$ purchase intention, $\mathrm{OTM}=$ model with observation traits, OTRM $=$ model with both observation and reflection traits.

$* p<.05$.

$* * p<.01$.

$* * * p<.001$.

\begin{tabular}{|c|c|c|}
\hline & Prospective consumers & Experienced consumers \\
\hline Less than $5000 \mathrm{RMB}$ & 4.15 & 3.76 \\
\hline $\begin{array}{l}\text { Between } 5001 \text { and 10,000 } \\
\text { RMB }\end{array}$ & 3.84 & 3.99 \\
\hline $\begin{array}{l}\text { Between } 10,001 \text { and } 20,000 \\
\text { RMB }\end{array}$ & 3.96 & 3.98 \\
\hline More than $20,000 \mathrm{RMB}$ & 3.33 & 4.13 \\
\hline
\end{tabular}

Table 8

Assessment of price importance.

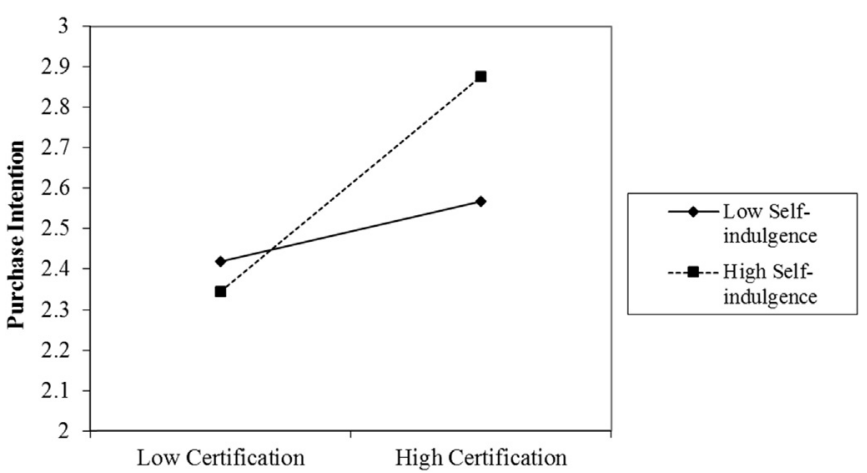

Fig. 3. Moderation effect of self-indulgence on the relationship between certification and purchase intention for PC.

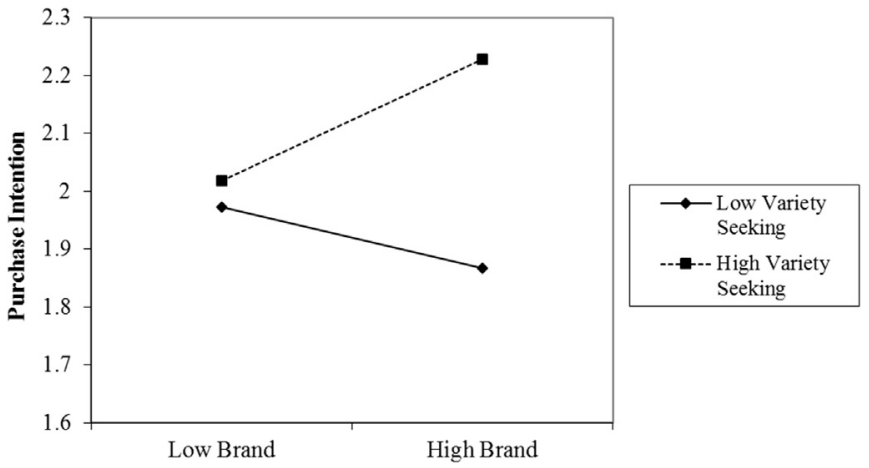

Fig. 4. Moderation effect of variety seeking on the relationship between brand and purchase intention for PC. 


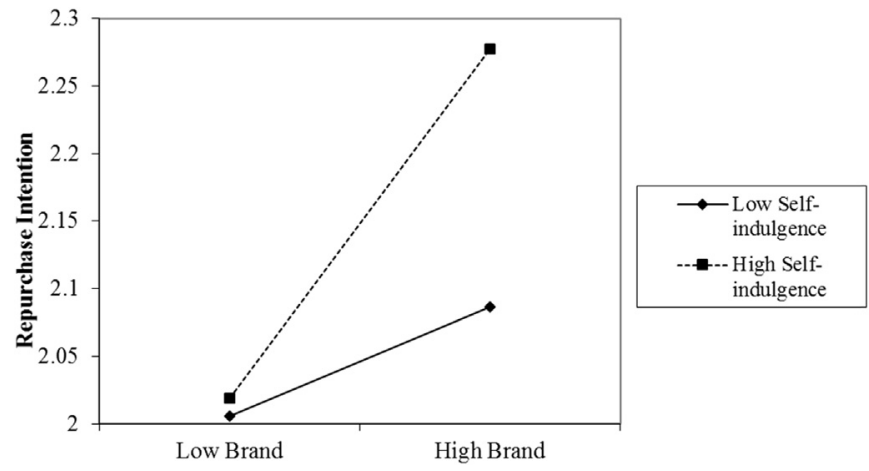

Fig. 5. Moderation effect of self-indulgence on the relationship between brand and repurchase intention for EC.

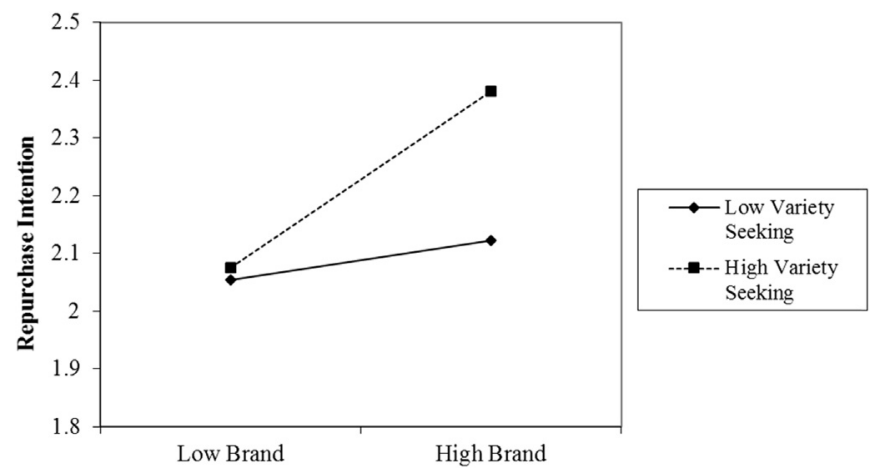

Fig. 6. Moderation effect of variety seeking on the relationship between brand and repurchase intention for EC.

intention for both prospective consumers and experienced consumers, and the changes in $\mathrm{R}^{2}$ were significant. Therefore, both $\mathrm{H} 2 \mathrm{a}$ and $\mathrm{H} 2 \mathrm{~b}$ were supported.

From the testing, price demonstrates a direct effect on purchase intention of prospective consumers. Hence, we analysed respondents' assessment of price importance over their wages (see Table 8). The results show that price is perceived more importantly by PC for those with monthly income of less than 5000 RMB. For EC, those who earned more than 20,000 have the highest score. In other words, high income earners in the case of PC are less concerned of prices. On the contrary, as shown in Table 8, EC with higher incomes are more conscious of the price.

$\mathrm{H} 4 \mathrm{a}$ and $4 \mathrm{~b}$ propose that individual purchase styles moderate the relationship between product traits and purchase intention. Results from moderation testing show that, in the case of PC, self-indulgence significantly moderates the relationship between certification and purchase intention $(\beta=.18, p<.01)$; whereas variety seeking moderates the relationship between brand and purchase intention $(\beta=.16$, $p<.05$ ). In the case of EC, self-indulgence moderates the relationship between brand and repurchase intention $(\beta=.07, p<.05)$; variety seeking moderates the relationship between brand and repurchase intention $(\beta=.11, p<.01)$. These findings are depicted in Fig.s $3-6$ following Aiken and West (1991). Overall, these results partially support H4b.

\section{Discussion and conclusions}

This study investigates the relationships among organic food quality traits that form consumers' perceived behavioural control, personal attributes manifest in individual purchase styles, and purchase intention with a focus on Chinese consumers. This investigation seeks to understand how Chinese consumers perceive and purchase "safe food" (organic food). In particular, the study analyses these relationships separately for individuals who have purchased and consumed organic food (referred to as EC in the current study) and those who have not (referred to as PC), in order to gain insights into organic food sales. This option is intended to help organic food producers and marketers better understand the market and seek for most appropriate means and strategies to market their products. The findings show that observation traits in general have no significant influences on either consumers' attitudes towards organic food or purchase intention for both EC and PC; whereas most reflection traits do. As proposed, reflection traits do explain additional variance in both quality assessment and purchase intention beyond observation traits. Consumers' purchase styles do have significant moderation effects on attitude and purchase intention in both groups. Detailed discussion of these findings is as follows.

\subsection{Organic food quality traits, quality assessment and purchase intention}

Prior to testing the proposed relationships, the selected traits associated with organic food were ranked to understand the relevant importance in consumers' assessment of the organic food quality. The results show that reflection traits have high scores than observation traits for both PC and EC. In particular, certification of the products is the most important factor in determining authenticity of organic food for both groups. Interestingly, PC scored all reflection traits higher than EC. This finding may suggest that PC without prior consumption experience believe these traits accounts for organic food quality.

In assessing the impact of observation traits on quality assessment and purchase intention, no significant results were found. As proposed, most reflection traits have significant impacts on quality assessment for both EC and PC. Price significantly affects PC's purchase intention. Organic food is rather expensive compared to conventional ones. Indeed, the post-hoc analysis shows that those with low wages in the case of PC rate price as the most important factor in their purchase. Probably price is one of the reasons that affect PC's purchase of organic food. However, for those who have purchased and consumed organic food, despite some with low wages, they still prefer expensive organic food. Their positive experience with organic food probably accounts for such preference.

The results show that labelling and certification are important factors in quality assessment and purchase intention. Labelling is particularly important for EC to assess organic food quality. Since they have had prior experience with organic food, EC are aware that labels convey important information of the product. Branding and heath effect also significantly affect EC's intention to purchase organic food again. These traits are reflective of ethical and safety cues. Consumers are unable to identify intrinsic quality of organic food from that of conventional products; they rely on theses cues to assess product quality and make their purchase decisions. Brand can serve as a means of creating differentiation of quality in consumers' minds (Phillips et al., 2014). Certification also conveys a legal means to ensure authenticity and quality of the product. Interestingly, government regulation has insignificant influence on either quality assessment or purchase intention for PC. This finding may suggest that Chinese consumers have little confidence in their government. Although EC believe that government control may affect product quality, the regulation per se is not adequate to ensure food quality.

The mediating testing shows that quality assessment does mediate the relationship between some reflection traits and intention to purchase and repurchase for PC and EC. Inclusion of quality assessment in the model enhances the predicting effect on purchasing intention. The findings indicate that reflection traits associated with organic food constitute consumers' assessment of the product quality and purchase. The partial mediation relationships suggest that both reflection traits and quality assessment account for organic food purchase. 


\subsection{The moderation testing}

The study shows that those who have self-indulgence tendency are more concerned of product certification and branding. Apparently organic food is more expensive than conventional ones. Self-indulgent individuals would buy them anyway as they believe organic food are safer, especially those with reliable certification and branding. These consumers are also price oriented. Post hoc analysis shows that EC with low wages rank price as the least important factor in purchasing organic food. These consumers have high scores of self-indulgence. These findings provide new insights for organic marketers. When organic food consumption is driven by consumers' purchase style (self-indulgence), the marketing strategy for promoting organic food should be adjusted accordingly.

Variety seeking demonstrates a positive moderation effect on the relationship between brand and purchase intention for both PC and EC. The results show that individuals who are rated high in variety seeking tend to be more brand conscious. Consuming organic food has become a fashion (e.g. Falguera et al., 2012; Kulmala et al., 2013). Consumers who tend to seek variety love fashion and trendy products. As indicated in this finding, they are more inclined to purchase branded organic food.

\section{Implications}

Instead of testing attitudes-intention-behaviour relationship as depicted in the popular TPB model, the current study proposes the quality attributes constituting perceived behavioural control in organic food purchase affect quality assessment and purchase intention. Personal attributes that are reflective of personal norms are modelled as moderators of food-related attributes - quality assessment - purchase intention relationship. Consequently, this study provides insights into original propositions of theory of planned behaviours. The study draws upon prevalent food safety scandals in China. The finding of personal norm (personal attributes) - attitude relationship is consistent with that of studies by Gotschi et al. (2007) and Tarkiainen and Sundqvist (2005).

Unlike prior research that has primarily focused on observation traits of organic food, the current study argues that traits that are reflective of ethical, environmental and safety issues have more impact on Chinese consumers' quality assessment and purchase intention. This view is consistent with Zhao et al.'s (2007) claim that observation traits are not sufficient to determine product quality as consumers are unable to differentiate organic from conventional products on the basis of these surface traits alone (see Zhao et al., 2007). Other researchers (e.g. Magnusson et al., 2003; Michaelidou and Hassan, 2008) also resonate with this view. The hierarchical testing of traits-purchase relationship and separate analysis for PC and EC provide insightful information for the relevant researchers and practitioners.

The findings of this study have particular implications for organic food producers and marketers. Only reflection traits are found to affect Chinese consumers' quality assessment and purchase intention. Some attributes (e.g. product certification) have direct and indirect influence on purchase intention for both PC and EC. For organic food marketers, the marketing endeavour to increase market share should be focused on the attributes that have potential to attract PC to purchase organic food and to stimulate EC to repurchase these products. Marketers should pay special attention to labelling and certification given its significant influence on quality assessment and purchase intention for both PC and EC. Labelling is reflective of product specifications, whereas certification is indicative of authenticity of organic products. These attributes are particularly important for Chinese consumers given food safety concerns. The significant moderating effects exerted by consumers' purchase style suggest that marketers should analyse consumers' lifestyle and personal traits in order to develop more appropriate marketing strategies to promote organic food.

\section{Limitations and future research}

Although every endeavour has been made to ensure methodological and statistical rigorousness in this study, some limitations must be acknowledged. The study was only undertaken in four cities in China. Although citizens in these cities are fairly representative of organic food consumers in this country, generalization of the findings may be limited. Future research should extend the sample into other cities. The survey was conducted in shopping malls. Random sampling on households at various locations may be more representative of the organic food market. Difference of the sample sizes of PC and EC may also affect the findings. Future research should attend to these limitations and provide a more holistic picture of organic food purchase.

\section{References}

Aertsens, J., Mondelaers, K., Verbeke, W., Buysse, J., Van Huylenbroeck, G., 2011. The influence of subjective and objective knowledge on attitude, motivations and consumption of organic food. Br. Food J. 113 (11), 1353-1378.

Aertsens, J., Verbeke, W., Mondelaers, K., Van Huylenbroeck, G., 2009. Personal determinants of organic food consumption: a review. Br. Food J. 111 (10), 1140-1167.

Aiken, L.S., West, S.G., 1991. Multiple Regression: Testing and Interpreting Interactions. Sage, New York.

Ajzen, I., 1991. The theory of planned behaviour. Organ. Behav. Human. Decis. Process. 50, 179-211.

Arvola, A., Vassallo, M., Dean, M., Lampila, P., Saba, A., Lähteenmäki, L., Shepherd, R., 2008. Predicting intentions to purchase organic food: the role of affective and moral attitudes in the Theory of Planned Behaviour. Appetite 50, 443-454.

Bamberg, S., Möser, G., 2007. Twenty years after Hines, Hungerford, and Tomera: a new meta-analysis of psycho-social determinants of pro-environmental behaviour. J. Environ. Psychol. 27, 14-25.

Bavec, F., Bavec, M., 2006. Organic Production and Use of Alternative Crops. Taylor \& Francis Croup, Boca Raton, FL.

Botonaki, A., Polymeros, K., Tsakiridou, E., Mattas, K., 2006. The role of food quality certification on consumers' food choices. Br. Food J. 108 (2), 77-90.

Bower, A.B., 2001. Highly attractive models in advertising and the women who loathe them: the implications of negative affect for spokesperson effectiveness. J. Advert. 30 (3), 51-63.

Chen, M.-F., 2007. Consumer attitudes and purchase intentions in relation to organic foods in Taiwan: moderating effects of food-related personality traits. Food Qual. Prefer. 18, 1008-1021.

Chen, M.-F., 2009. Attitude toward organic foods among Taiwanese as related to health consciousness, environmental attitudes, and the mediating effects of a healthy lifestyle. Br. Food J. 111 (2), 165-178.

Chen, J., Lobo, A., 2012. Organic food products in China: determinants of consumers' purchase intentions, The International Review of Retail. Distrib Consum Rese 22 (3), 293-314.

Chryssochoidis, G., 2000. Repercussions of consumer confusion for late introduced differentiated products. Eur. J. Mark. 34 (5/6), 705-722.

Cronin Jr., J.J., Brady, M.K., Hult, G.T.M., 2000. Assessing the effects of quality, value, and customer satisfaction on consumer behavioral intentions in service environments. J. Retail. 76, 193-218.

Dean, M., Raats, M.M., Shepherd, R., 2008. Moral concerns and consumer choice of fresh and processed organic foods. J. Appl. Social Psychol. 38, 2088-2107.

Drichoutis, A.C., Lazaridis, P., Nayga Jr, R.M., 2007. An assessment of product class involvement in food-purchasing behavior. Eur. J. Mark. 41 (7/8), 888-914.

Eisinger-Watzl, M., Wittig, F., Heuer, T., Hoffmann, I., 2015. Customers purchasing organic food-Do they live healthier? Results of the German National Nutrition survey II. Eur. J. Nutr. Food Saf. 5, 59-71.

Euromonitor International, 2015. Organic Packaged Food in China. Available at $\langle\mathrm{http} / / /$ www.portal.euromonitor.com/Portal/Pages/Search/SearchResultsList.aspx > (accessed 20 August 2017).

Falguera, V., Aliguer, N., Falguera, M., 2012. An integrated approach to current trends in food consumption: moving toward functional and organic products? Food Control 26, 274-281.

Fornell, C., Larcker, D.F., 1981. Structural Equation Models with Unobservable Variables and Measurement Error: algebra and Statistics. J. Mark. Res. 18, 382-388.

Fotopoulos, C., Krystallis, A., 2002. Purchasing motives and profile of the Greek organic consumer: a countrywide survey. Br. Food J. 104 (8/9), 730-765.

Gotschi, E., Vogel, S., Lindenthal, T., 2007. High School Students' Attitudes and Behaviour Towards Organic Products: Survey Results from Vienna. Institute for Sustainable Economic Develop, DoE aSS, University of Natural Resources and Applied Life Sciences, Vienna.

Gundersen, H.J.G., Jensen, E.B., 1987. The efficiency of systematic sampling in stereology and its prediction. J. Microsc. 147, 229-263.

Ho, P., Vermeer, E.B., Zhao, J.H., 2006. Biotechnology and Food Safety in China: consumers' Acceptance or Resistance? Dev. Change 37, 227-254.

Honkanen, P., Verplanken, B., Olsen, S.O., 2006. Ethical values and motives driving organic food choice. J. Consum. Behav. 5, 420-430.

Howard, P.H., Allen, P., 2006. Beyond organic: consumer interest in new labelling schemes in the Central Coast of California. Int. J. Consum. Stud. 30, 439-451. 
Hu, L., Bentler, P.M., 1999. Cutoff criteria for fit indexes in covariance structure analysis: conventional criteria versus new alternatives. Struct. Equ. Model.: A Multidiscip. J. 6 (1), 1-55.

Hughner, R.S., McDonagh, P., Prothero, A., Shultz II, C.J., Stanton, J., 2007. Who are organic food consumers? A compilation and review of why people purchase organic food. J. Consum. Behav. 6, 94-110.

Kaiser, F.G., 2006. A moral extension of the theory of planned behavior: norms and anticipated feelings of regret in conservationism. Personal. Individ. Differ. 41, 71-81.

Krystallis, A., Chryssohoidis, G., 2005. Consumers' willingness to pay for organic food: factors that affect it and variation per organic product type. Br. Food J. 107 (5), 320-343.

Krystallis, A., Fotopoulos, C., Zotos, Y., 2006. Organic consumers' profile and their willingness to pay (WTP) for selected organic food products in Greece. J. Int. Consum. Mark. 19 (1), 81-106.

Kulmala, M., Mesiranta, N., Tuominen, P., 2013. Organic and amplified eWOM in consumer fashion blogs. J. Fash. Mark. Manag.: Int. J. 17 (1), 20-37.

Kuhar, A., Juvancic, L., 2010. Determinants of purchasing behaviour for organic and integrated fruits and vegetables in Slovenia. Agric. Econ. Rev. 11 (2), 70-83.

Lea, E., Worsley, T., 2005. Australians' organic food beliefs, demographics and values. Br. Food J. 107 (11), 855-869.

Lee, H.-J., Yun, Z.S., 2015. Consumers' perceptions of organic food attributes and cognitive and affective attitudes as determinants of their purchase intentions toward organic food. Food Qual. Prefer. 39, 259-267.

Li, Y., Cheng, L.Z., Ren, G.Y., 2005. Products difference and consumption decision of hazard free agricultural products - a survey in Jiaxing city. Stat. Sci. Pract. 2, 22-24.

Lobo, A., Chen, J., 2012. Marketing of organic food in urban China: an analysis of consumers' lifestyle segments. J. Int. Mark. Export. 17 (1), 14-26.

Lockie, S., Lyons, K., Lawrence, G., Mummery, K., 2002. Eating 'green': motivations behind organic food consumption in Australia. Sociol. Rural. 42, 23-40.

Magnusson, M.K., Arvola, A., Hursti, U.K., Åberg, L., Sjödén, P., 2003. Choice of organic foods is related to perceived consequences for human health and to environmentally friendly behaviour. Appetite 40, 109-117.

McEachern, M.G., Willock, J., 2004. Producers and consumers of organic meat: a focus on attitudes and motivations. Br. Food J. 106 (7), 534-552.

Michaelidou, N., Hassan, L.M., 2008. The role of health consciousness, food safety concern and ethical identity on attitudes and intentions towards organic food. Int. J. Consum. Stud. 32, 163-170.

Millock, K., Wier, M., Andersen, L.M., 2004. Consumer demand for organic foods - attitudes, values and purchasing behaviour, paper presented at Proceedings of the Thirteenth Annual Conference of European Association of Environmental and Resource Economics, Budapest, Hungary, June 25-28.

Moore, O., 2006. Understanding postorganic fresh fruit and vegetable consumers at participatory farmers' markets in Ireland: reflexivity, trust and social movements. Int. J. Consum. Stud. 30, 416-426.

O' Donovan, P., McCarthy, M., 2002. Irish consumer preference for organic meat. Br. Food
J. 104 (3-5), 353-370.

Padel, S., Foster, C., 2005. Exploring the gap between attitudes and behaviour: understanding why consumers buy or do not buy organic food. Br. Food J. 107 (8), 606-625.

Phillips, B.J., McQuarrie, E.F., Griffin, W.G., 2014. How visual brand identity shapes Consumer response. Psychol. Mark. 31, 225-236.

Rimal, A.P., Moon, W., Balasubramanian, S., 2005. Agro-biotechnology and organic food purchase in the United Kingdom. Br. Food J. 107 (2), 84-97.

Roddy, G., Cowan, C.A., Hutchinson, G., 1996. Consumer attitudes and behaviour to organic foods in Ireland. J. Int. Consum. Mark. 9 (2), 41-63.

Shepherd, R., Magnusson, M., Sjödén, P., 2005. Determinants of consumer behavior related to organic foods. AMBIO: A J. Human. Environ. 34 (4), 352-359.

Röhr, A., Lüddecke, K., Drusch, S., Müller, M.J., Alvensleben, R. v., 2005. Food quality and safety-consumer perception and public health concern. Food Control 16, 649-655.

Siamagka, N., Balabanis, G., 2015. Revisiting consumer ethnocentrism: review, reconceptualization, and empirical testing. J. Int. Mark. 23, 66-86.

Stern, P.C., 2000. New environmental theories: toward a coherent theory of environmentally significant behavior. J. Social. Issues 56, 407-424.

Tarkiainen, A., Sundqvist, S., 2005. Subjective norms, attitudes and intentions of Finnish consumers in buying organic food. Br. Food J. 107 (11), 808-822.

Thøgersen, J., 2007a. Consumer decision making with regard to organic food products. In: Vaz, M.T.D.N., Vaz, P., Nijkamp, P., Rastoin, J.L. (Eds.), Traditional Food Production Facing Sustainability: A European Challenge. Ashgate, Farnham, pp. 173-192.

Thøgersen, J., 2007b. The motivational roots of norms for environmentally responsible behaviour, paper presented at Nordic Consumer Policy Research Conference, Helsinki.

Torjusen, H., Lieblein, G., Wandel, M., Francis, C.A., 2001. Food system orientation and quality perception among consumers and producers of organic food in Hedmark County, Norway. Food Qual. Prefer. 12, 207-216.

Tregear, A., Dent, J.B., McGregor, M.J., 1994. The demand for organically grown produce. Br. Food J. 96 (4), 21-25.

Tsakiridou, E., Boutsouki, C., Zotos, Y., Mattas, K., 2008. Attitudes and behaviour towards organic products: an exploratory study. Int. J. Retail Distrib. Manag. 36 (2), 158-175.

Tsakiridou, E., Mattas, K., Tzimitra-Kalogianni, I., 2006. The influence of consumer characteristics and attitudes on the demand for organic olive oil. J. Int. Food Agribus. Mark. 18 (3/4), 23-31.

Williams, P.R.D., Hammitt, J.K., 2000. A comparison of organic and conventional fresh produce buyers in the Boston area. Risk Anal. 20, 735-746.

Wulf, K.D., Odekerken-Schröder, G., Lacobucci, D., 2001. Investments in consumer relationships: a cross-country and cross-industry exploration. J. Mark. 65 (4), 33-50.

Zhao, X., Chambers IV, E., Matta, Z., Loughin, T.M., Edward, E., Carey, E.E., 2007. Consumer sensory analysis of organically and conventionally grown vegetables. J. Food Sci. 72, 87-91. 